\title{
Consensus Recommendations from EXPeRT/PARTN-ER Groups for the Diagnosis and Therapy of Sex Cord Stromal Tumors in Children and Adolescents
}

Dominik T. Schneider ${ }^{1}$, Daniel Orbach ${ }^{2}$, Tal Ben-Ami ${ }^{3}$, Ewa Bien ${ }^{4}$, Gianni Bisogno ${ }^{5}$, Ines Brecht $^{6}$, Giovanni Cecchetto ${ }^{7}$, Andrea Ferrari ${ }^{8}$, Jan Godziński ${ }^{9}$, Dragana Janic ${ }^{10}$, Ricardo Lopez $^{11}$, Apostolos Pourtsidis ${ }^{12}$, Jelena Roganovic ${ }^{13}$, Kris Ann Schultz ${ }^{14}$, Teresa Stachowicz-Stencel ${ }^{15}$, and Brice Fresneau ${ }^{16}$

${ }^{1}$ Klinikum Dortmund

${ }^{2}$ Institut Curie

${ }^{3}$ Kaplan Medical Center

${ }^{4}$ Medical University, Gdansk

${ }^{5}$ Division of Hematology/Oncology

${ }^{6}$ University of Tübingen

${ }^{7}$ Universita degli Studi di Padova Scuola di Medicina e Chirurgia

${ }^{8}$ Istituto Nazionale Tumori, Milano

${ }^{9}$ Marciniak Hospital

${ }^{10}$ University of Belgrade, University of Children's Hospital

${ }^{11}$ Cruces University Hospital

${ }^{12}$ Panagiotis and Aglaia Kyriakou Children's Hospital

${ }^{13}$ Clinical Hospital Center Rijeka

${ }^{14}$ University of Minnesota

${ }^{15}$ Medical University of Gdansk

${ }^{16}$ GUSTAVE ROUSSY

February 16, 2021

\begin{abstract}
As part of the European Union-funded project designated PARTN-ER, the European Cooperative Study Group for Pediatric Rare Tumors (EXPeRT) is continuously developing consensus recommendations in order to harmonize standard care for very rare solid tumors of children and adolescents. This paper presents the internationally recognized recommendations for the diagnosis and treatment of sex cord stromal tumors (SCST). The clinical approach to sex cord stromal tumors of the testis (TSCST) and ovary (OSCST) depends on histological differentiation and tumor stage. Virtually all TSCSTs present as localized non-metastatic tumors, with excellent prognosis after complete resection. In contrast, the prognosis of OSCSTs may be adversely affected by tumor spillage during surgery or presence of metastases. In these cases, cisplatin-based chemotherapy is recommended. Of note, some SCSTs may develop in the context of tumor predisposition syndromes e.g. DICER-1, so that specific follow-up is indicated. SCSTs should be diagnosed and treated according to standardized recommendations that include reference pathology, genetic testing for tumor predisposition syndromes in selected cases, and stratified adjuvant chemotherapy in patients with unfavorable risk profile. To ensure high quality of diagnosis and therapy, patients should be enrolled into prospective registries.
\end{abstract}




\section{Consensus Recommendations from EXPeRT/PARTN-ER Groups for the Diagnosis and Ther-}

apy of Sex Cord Stromal Tumors in Children and Adolescents

Authors:

Dominik T. Schneider ${ }^{1}$, Daniel Orbach ${ }^{2}$, Tal Ben Ami ${ }^{3}$, Ewa Bien ${ }^{4}$, Gianni Bisogno ${ }^{5}$, Ines B. Brecht ${ }^{6}$, Giovanni Cecchetto ${ }^{7}$, Andrea Ferrari ${ }^{8}$, Jan Godzinski ${ }^{9}$, Dragana Janic ${ }^{10}$, Ricardo Lopez Almaraz ${ }^{11}$, Apostolos Pourtsidis $^{12}$, Jelena Roganovic ${ }^{13}$, Kris Ann P. Schultz ${ }^{14}$, Teresa Stachowicz-Stencel ${ }^{4}$, Brice Fresneau ${ }^{15,16}$

Affiliations:

1. Clinic of Pediatrics, Dortmund Municipal Hospital, Dortmund, Germany

2. SIREDO Oncology Center (Care, Innovation and Research for Children, Adolescents and Young Adults with cancer), Institut Curie, PSL University, Paris, France

3. Pediatric Hematology Unit, Kaplan Medical Center, Rehovot, Israel;

4. Department of Pediatrics, Hematology and Oncology, Medical University, Gdansk, Poland

5. Clinic of Pediatric Hematology and Oncology, University of Padova, Italy

6. Clinic of Pediatric Hematology and Oncology, University of Tübingen, Germany

7. Clinic of Pediatric Surgery, University of Padova, Italy

8. Istituto Tumori, Milan, Italy

9. Department of Pediatric Surgery, Marciniak Hospital, Wroclaw, Poland and Department of Pediatric Traumatology and Emergency Medicine, Medical University, Wroclaw, Poland

10. Department of Hematology and Oncology, University Children's Hospital, University of Belgrade, Belgrade, Serbia

11. Pediatric Hematology Oncology Department, Hospital Universitario de Cruces, Barakaldo-Bizkaia, Spain

12. Pediatric Oncology Unit, Aglaia Kyriakou Children's Hospital, Athens, Greece

13. Department of Pediatrics, Clinical Hospital Center Rijeka, University of Rijeka, Croatia

14. International Ovarian and Testicular Stromal Tumor Registry, Cancer and Blood Disorders, Children's Minnesota, Minneapolis, MN,U.S.A.

15. Gustave Roussy, Université Paris-Saclay, Department of Pediatric Oncology, Villejuif, F-94805, France

16. Paris-Saclay University, Paris-Sud University

\section{Correspondence to:}

Professor Dr. Dominik T. Schneider,

Klinik für Kinder- und Jugendmedizin, Beurhausstr. 40, D-44137 Dortmund, Germany

$\mathrm{T}:+49-231-95321680$;

F: +49-231-95321047;

E: dominik.schneider@klinikumdo.dedominik.schneider@klinikumdo.de

Short running title: Recommendations for sex cord stromal tumors

Key words: rare tumors, sex cord stromal tumors, ovary, testis, guidelines

Conflict of interest: All the authors have no conflicts of interest to disclose.

Funding source: The PARTN-ER project (ERN-PAEDCAN Partner Paediatric Rare Tumours Network European Registry) is financed and co-funded by the Health Program of the European Union which did not take part in the writing of these guidelines ( ${ }^{\text {rd }}$ Health Programme Call: HP-PJ-06-2016: Rare diseases support for New Registries. CHAFEA Grant Nr: 777336 - HP-PJ-06-2016).

Financial disclosure: All the authors have no financial relationships relevant to this article to disclose. 


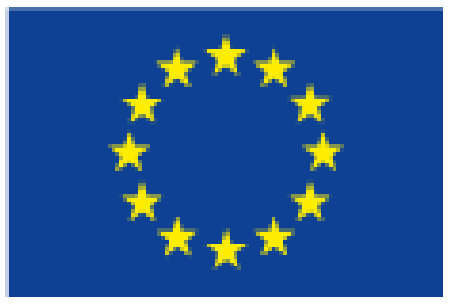

\title{
Co-funded by the Health Programme of the European Union
}

Text word count : 3051

Abstract word count : 188

Number of tables : 5

Number of figures: 0

Supplemental files: 0

List of Abbreviations:

\begin{tabular}{ll}
\hline AFP & Alpha fetoprotein \\
\hline CT & Computerized tomography \\
DHEAS & Dehydroepiandrosterone \\
ERN PaedCan & European Reference Network for Paediatric Cancer \\
EXPeRT & European Cooperative Study Group for Pediatric Rare Tumors \\
FIGO & International Federation of Gynecology and Obstetrics \\
GCT & Germ Cell Tumor \\
GrCT & Granulosa Cell Tumor \\
FSH & Follicle Stimulating Hormone \\
LH & Luteinizing Hormone \\
MRI & Magnetic Resonance Imaging \\
PARTN-ER & Paediatric Rare Tumours Network - European Registry \\
SLCT & Sertoli-Leydig Cell Tumor \\
SCSTs & Sex cord stromal tumors \\
HPLAP & Human alkaline placenta like phosphatase \\
VRT & Very rare tumor \\
\hline
\end{tabular}

\begin{abstract}
As part of the European Union-funded project designated PARTN-ER, the European Cooperative Study Group for Pediatric Rare Tumors (EXPeRT) is continuously developing consensus recommendations in order to harmonize standard care for very rare solid tumors of children and adolescents. This paper presents the internationally recognized recommendations for the diagnosis and treatment of sex cord stromal tumors (SCST).

The clinical approach to sex cord stromal tumors of the testis (TSCST) and ovary (OSCST) depends on histological differentiation and tumor stage. Virtually all TSCSTs present as localized non-metastatic tumors, with excellent prognosis after complete resection. In contrast, the prognosis of OSCSTs may be adversely affected by tumor spillage during surgery or presence of metastases. In these cases, cisplatin-based chemotherapy is recommended. Of note, some SCSTs may develop in the context of tumor predisposition syndromes e.g. DICER-1, so that specific follow-up is indicated.
\end{abstract}

SCSTs should be diagnosed and treated according to standardized recommendations that include reference 
pathology, genetic testing for tumor predisposition syndromes in selected cases, and stratified adjuvant chemotherapy in patients with unfavorable risk profile. To ensure high quality of diagnosis and therapy, patients should be enrolled into prospective registries.

\section{Introduction}

Sex cord stromal tumors (SCSTs) represent a heterogeneous group of rare gonadal tumors that represent approximately $10 \%$ of all gonadal tumors during childhood. ${ }^{1}$ SCSTs develop from the non-germ cell component of the gonads. Physiologically, these cells support germ cell maturation in their microenvironment. Furthermore, they may produce sex hormones, and so may the corresponding tumors. The rarity and heterogeneity of SCSTs, and the difficulty in the correct histopathologic classification leave a significant uncertainty with regard to the optimal clinical. Of note, some subtypes are associated with constitutional genetic aberrations (e.g. DICER1 mutations) and thus, they may be part of an underlying cancer predisposition and require specific follow-up. ${ }^{2-4}$

This paper presents the internationally harmonized recommendations for the diagnosis and treatment of children and adolescents with SCSTs, established by the EXPeRT within the EU-funded project called PARTN-ER - Paediatric Rare Tumours Network - European Registry. The methodology of the process development under the auspices of the European Reference Network for Paediatric Cancer (ERN PaedCan) - has been already described (Orbach et al, PBC 2021)

\section{Testicular Sex Cord Stromal Tumors (TSCST)}

Patients with TSCSTs typically present with indolent intra-testicular mass. Apart from benign disorders such as varicocele, cysts etc., malignant germ cell tumors (GCT) and teratomas are the most relevant differential diagnosis. ${ }^{1}$ Beyond infancy, malignant GCTs are almost exclusively yolk sac tumors, characterized by serum secretion of alpha-fetoprotein (AFP). After the onset of puberty, other histological types such as seminoma, embryonal carcinoma and choriocarcinoma may develop, being clinically categorized into seminoma and non-seminoma.

Most of TSCSTs present as painless testicular swelling. The only specific clinical manifestation that distinguishes TSCSTs from other testicular tumors of different histological origin is its hormonal secretion. However hormonal activity is mostly observed in Leydig cell tumors, a very rare type of pediatric SCSTs in which testosterone secretion is responsible of isosexual precocious pseudopuberty in prepubertal boys or gynecomastia due to aromatization of testosterone to estradiol in Leydig cells or adipose tissue. ${ }^{5}$ Large-cell calcifying Sertoli cell tumors are another histological subtype of TSCSTs encountered in prepubertal boys, teenagers and young adults, which could be revealed by endocrine signs, in particular gynecomastia due to aromatase activity in Sertoli tumor cells. The main other pediatric TSCST is juvenile granulosa cell tumor (GrCT), mostly diagnosed in the first year of life as painless testicular swelling. All these pediatric TSCSTs have a benign course after curative total orchiectomy. A genetic susceptibility syndrome is rare but has to be explored in cases of large-cell calcifying Sertoli cell tumors which are associated with Peutz-Jeghers syndrome (STK11 mutations) and Carney complex (PRKAR1A mutations).

\section{Diagnostic work-up}

\section{Anamnesis}

Standard anamnesis [Level I, Grade A].

Specific query regarding tumor predisposition syndromes (e.g. Peutz-Jeghers syndrome) [Level V, Grade B].

Physical examination 
Palpation of both testes, determination of pubertal stage according to the Tanner scale [Level I, Grade A].

Complete physical examination, focussing on abdominal palpation [Level I, grade A].

\section{Laboratory investigation}

- All patients: Serum AFP (correlate to age-related reference levels) to exclude malignant secreting yolk sac tumor [Level I, Grade A].

- Adolescents: Serum B-HCG and total HCG to exclude secreting GCTs [Level I, Grade A].

- Serum inhibin, estrogen, testosterone, DHEAS, FSH and LH in cases of endocrinological symptoms such as precocious puberty or gynecomastia [Level I, Grade B].

- Routine genetic testing for cancer predisposition in all patients is not recommended. However, based on family and individual history and exam, genetic testing of individual patients can be considered in the evaluation for tumor predisposition. In large cell calcifying Sertoli tumors, Peutz-Jeghers syndrome should be excluded. Single cases of pediatric testicular stromal tumors have been described in children with germline DICER1 pathogenic variation (one Sertoli and one Leydig cell tumor) (L. Golmard et al, in press) [Level V, Grade B].

\section{Imaging}

- Ultrasound of both testes, measurement of tumor size, exclusion of paratesticular tumor [Level I, Grade A].

- Testicular MRI is currently used more frequently to distinguish between benign lesions, Leydig cell tumors, other SCSTs and GCTs [Level III, Grade C].

- Pelvic-abdominal ultrasound focussing on paraaortal lymph nodes in case of right-sided and renal lymph nodes in case of the left-sides tumors is recommended [Level II, Grade A].

- TSCSTs are most commonly detected as small tumors, limited to the testis, and they extremely rarely metastasize. ${ }^{6-8}$ Thus, more intensive staging is not recommended in case of SCSTs in prepubertal patients [Level IV, Grade A].

- Pelvic-abdominal MRI is recommended only if ultrasound does not allow assessment of the retroperitoneal lymph nodes [Level III, Grade A]. CT can also be used but bears the disadvantage of radiation exposure in children [Level III, Grade B].

- Chest X-ray can be done, however is not recommended to avoid radiation exposure, as lung metastases are not expected [Level III, grade D]. In particular, chest CT is not recommended [Level II, Grade E].

\section{Therapy}

- Orchiectomy after high inguinal incision and first ligation of the spermatic cord constitutes the gold standard and constitutes the only treatment for most patients [Level III, Grade A]. ${ }^{6,} 7$

- Considering the patient's potential wish, a testicular prosthesis can be inserted during the same surgical session [Level IV, Grade B].

- Considering the overall favourable prognosis, there has been some debate as to whether tumor excision after scrotal excision or organ sparing surgery (e.g. enucleation of the tumor) may also be appropriate. These strategies have not yet been validated prospectively, and it is unclear whether organ sparing surgery may indeed contribute to further reproductive function and increase quality of life [Level IV, Grade C]. ${ }^{9}$

- In case of complete but organ sparing enucleation of a testicular SCST with an inguinal approach, a second look surgery and orchiectomy is not mandatory, at least in prepubertal children with nonmetastatic tumors [Level IV, Grade D]. Moreover, in the same group of patients a second look surgery in case of transscrotal surgery is not considered mandatory, either [Level IV, Grade D].

- Organ sparing surgery should be attempted as an individual approach in non-metastatic bilateral tumors [Level IV, Grade B]].

- Biopsy of a contralateral testis, which is not suspicious on palpation and/or ultrasound, is not required [Level IV, Grade D]. 
- Retroperitoneal lymph node dissection is recommended only in rare cases of suspicious lymph node spread detected by ultrasound and/or MRI [Level IV, Grade B].

- The extremely rare metastatic tumor should be treated according to the corresponding concept for metastatic OSCST [Level V, Grade B]. ${ }^{1}$

\section{Follow-up (FU)}

- Despite the excellent prognosis, regular follow-up is recommended at least for the first two years [Level III, Grade A]. As up to $5 \%$ of patients may develop metachronous contralateral tumors, long-term follow-up may be offered, in particular in patients with suspected genetic predisposition (Table I ) [Level IV, Grade B].

- Follow-up investigations include anamnesis, physical examination and measurement of serum tumor markers only, if these have been elevated peri-operatively [Level IV, Grade A].

- Imaging follow-up includes pelvic, abdominal and scrotal ultrasound [Level IV, Grade A].

- Abdominal and pelvic MRI is recommended in case of equivocal findings on US during follow-up [Level IV, Grade A].

- Routine chest X-ray is not recommended for follow-up [Level IV, Grade E].

\section{Ovarian Sex Cord Stromal Tumors (OSCSTs)}

Patients with OSCSTs characteristically present with abdominal distension and may often suffer from abdominal discomfort and pain ${ }^{1}$. Hormone secreting tumors may present with signs of precocious puberty such as breast swelling, pubic hair, vaginal bleeding - characteristic of estrogen-secreting GrCTs - or virilisation and hirsutism - characteristic of androgen-secreting SLCTs. ${ }^{8}$ Some patients may present with symptoms of acute abdomen, caused by adnexal/ovarian torsion. Malignant GCTs and small cell carcinomas of the ovary, hypercalcemic type (SMARCA4 deficient) present the two most relevant differential diagnoses of OSCSTs. OSCSTs are different from GCTs in terms of their clinical presentation and their biology including associated genetic tumor predisposition syndromes. ${ }^{10}$

OSCSTs are histologically heterogeneous and include GrCTs, SLCTs, pure Sertoli cell and Leydig cell tumors, as well as theca and granulosa-theca tumors, sclerosing stromal tumors, sex cord-stromal tumors with annular tubules, and gynandroblastomas with simultaneous Sertoli and granulosa cell differentiation. They may arise in the context of several defined hereditary disorders. Juvenile GrCTs may be associated with multiple enchondromatosis, syn. Ollier's disease. ${ }^{11,12}$ Otherwise, no pathognomonic genetic aberration has been defined for juvenile GrCTs, but approximately one third may show point mutations of stimulatory $\mathrm{G}$ proteins. ${ }^{13}$

SLCTs are consistently associated with mutations of the DICER1gene. ${ }^{3,14,15}$ A report from the International Ovarian and Testicular (OTST) Registry found germline DICER1 mutations in approximately half of patients with SLCTs ${ }^{4}$. In this group, a spectrum of other cancers has been reported, of which thyroid cancer was seen in $4 / 25$ patients. These findings have significant impact on long-term follow-up of these patients and the surveillance of potentially affected family members. ${ }^{16}$

Last, there is a pronounced association of Peutz-Jeghers syndrome with sex cord stromal tumors with annular tubules (SCTAT) of both the testis and ovary. ${ }^{12,}{ }^{17}$ Approximately one third of SCTAT appear to develop in the context of Peutz-Jeghers syndrome. These tumors usually develop at a younger age than in otherwise healthy patients and may develop bilaterally.

\section{Diagnostic work-up (Table III)}

\section{Anamnesis}


- Standard anamnesis [Level I, Grade A]

- Gynaecological and pubertal development according to Tanner scale [Level I, Grade A]

- Query for thyroid disease such as multinodular goitre in the patient and her family (DICER1 syndrome) [Level II, Grade B]. ${ }^{3}$

- Specific query regarding tumor predisposition syndromes in the family, including tumors which may be associated with DICER1 pathogenic variation (e.g. pleuropulmonary blastoma, pineoblastoma etc.) [Level II, Grade A]. ${ }^{14}$

\section{Physical examination}

Complete physical examination, focussing on abdominal palpation, pubertal status, signs of virilisation and hirsutism [Level I, Grade A].

\section{Laboratory investigation}

- Serum AFP may be elevated in $>10 \%$ of SLCTs, in particular in retiform subtype. ${ }^{18}$ Tumor markers are completed by HCG/B-HCG to exclude secreting GCT. Serum CA125 can serve as a sensitive ovarian tumor marker during follow-up. ${ }^{19}$ Elevated calcium may indicate ovarian small cell carcinoma, hypercalcemic type, but may occasionally be seen in other ovarian tumors. [Level II, Grade A]

- Serum Inhibin and anti-Mullerian hormone, Estradiol, Testosterone, DHEAS / LH /FSH [Level II, Grade A].

- DICER1 testing should be offered to patients with SLCTs or gynandroblastoma - after prior genetic counselling [Level II, Grade A]. ${ }^{20}$

- Testing of thyroid hormones and thyroid ultrasound in cases of SLCTs, suspected or proven for DICER1 mutation - at diagnosis, and at regular intervals (e.g. every two years) during follow-up [Level II, Grade $\mathrm{B}] .^{3}$

- Prior to start of chemotherapy, hepatic, hematologic and renal functions must be evaluated and audiometry should be performed [Level II, Grade A].

\section{Imaging}

- Abdominal ultrasound focussing on the pelvis, ovaries, para-aortal lymph nodes (right ovarian tumor) and renal lymph nodes (left ovarian tumor) [Level II, Grade A].

- Abdominal and pelvic MRI [Level IV, Grade A].

- Chest X-ray or low-dose chest CT. Comment: OSCST extremely rarely metastasize at distant sites, almost never beyond the diaphragm. Most metastases occur within the abdominal cavity, leading to peritoneal tumor spread, or to the locoregional pelvic or retroperitoneal lymph nodes [Level IV, Grade $\mathrm{B}] .^{8,21-23}$

\section{Pathology and staging}

- Ovarian biopsy is strongly discouraged at diagnosis [Level III, grade E].

- Pathological assessment should include evaluation for capsule rupture, capsular invasion, subtyping of OSCSTs, grading (grade of immaturity in SLCTs), and description of prognostic histologic factors such as heterologous elements in SLCTs, mitotic rate in GrCTs [Level II, Grade A]. Pathologic samples should be evaluated by an experienced gyneco-/pediatric pathologist, a central reference pathologist review is recommended [Level IV, Grade A] ${ }^{21}$

- FOXL2 genetic assessment could be performed in GrCTs to distinguish juvenile and adult types.

- SCSTs should be staged according to the updated staging system of the International Federation of Gyneco-oncology (FIGO) for epithelial ovarian cancer [Level IV, Grade B] (Table II). ${ }^{18,24,24,25}$

\section{Therapy}

\section{Surgery}


- Since most tumors present as localized, stage FIGO Ia tumors, fertility sparing surgery, i.e. tumor resection by oophorectomy or adnexectomy will constitute the only therapy of these tumors [Level IV, Grade A]. ${ }^{8}, 22,23,25$

- Tumor resection with oophorectomy or adnexectomy should be the first surgical care [Level III; grade A]. Prior biopsy is discouraged [Level II, grade E].

- Median laparotomy constitutes the standard surgical approach in adults [Level II, Grade A], but in children also a sub-umbilical transverse incision or a Pfannenstil laparotomy can be accepted (depending on the size of the tumor and the initial tumor spread), which both allow for a good tumor exposure and a better cosmetic result [Level III, Grade B]. In case of small tumors, laparoscopic resection may be performed by experienced surgeons [Level IV, grade C]. However, oncologic criteria must be respected also with minimally invasive procedures [Level II, grade A]. Tumor rupture, puncture or any other violation of the tumor capsule have to be avoided stringently [Level IV, Grade E] ${ }^{26}$

- Staging includes cytological evaluation of ascites and/or peritoneal washings in absence of ascites, ideally before tumor mobilisation [Level IV, Grade B]. ${ }^{25}$

- Staging includes inspection and palpation of the contralateral ovary, inspection of the peritoneal cavity, focussing on the pelvis, pouch of Douglas and diaphragmatic cupola, with biopsy of any suspicious lesions, inspection and biopsy of any suspicious lymph nodes [Level IV, Grade B]. ${ }^{25}$

- Tumors confined to the ovary should be resected via ovariectomy; in cases of pelvic adhesion/infiltration, ipsilateral adnexectomy has to be performed [Level IV, Grade B]. ${ }^{25}$

- In cases of adhesions to the omentum, omentectomy is recommended; routine omentectomy is not required, if unsuspicious [Level IV, Grade B].

- In cases of bilateral tumors, ovary sparing tumor resection may be considered as an individual approach by an experienced surgeon and with appropriate equipment [Level V, Grade B]. ${ }^{25}$

- Routine retroperitoneal lymph node dissection is not recommended, if unsuspicious [Level IV, Grade B].

- Biopsy of an unsuspicious (in palpation and by ultrasound) contralateral ovary is not required [Level IV, Grade B].

- There is no role for debulking surgery (apart from palliative surgery). Hysterectomy as well as contralateral ovariectomy or other mutilating surgery should never be performed as an upfront surgery. Instead, inoperable tumors should be cautiously biopsied in order to assure the pathological diagnosis, and upfront chemotherapy should be initiated followed by delayed tumor resection [Level IV, Grade $\mathrm{A}] .{ }^{25}$

\section{Adjuvant Therapy including Chemotherapy (Table IV)}

- Stage IA/IB tumors do not require any adjuvant chemotherapy, in particular if histology shows good to intermediate differentiation; in selected patients with specific histologic criteria e.g. sarcomatous elements within SLCT, adjuvant chemotherapy can be discussed after individual consultation [Level III, Grade E]. ${ }^{1,8,22,23}$

- In stage IC juvenile GrCTs, chemotherapy is certainly recommended in case of pre-operative spontaneous tumor rupture (FIGO IC2) and/or malignant ascites (FIGO IC3) [Level IV, Grade A]. The indication for chemotherapy is disputable in stage IC1 juvenile GrCTs if intraoperative tumor spread occurs and appropriate surgical management (peritoneal washings) has been performed (FIGO Stage IC1) [Level IV, Grade C]. ${ }^{26}$

- Adjuvant chemotherapy is recommended in all stage IC SLCTs, irrespective of the time of the tumor rupture [Level IV, Grade A]. ${ }^{18}$

- Adjuvant chemotherapy is recommended in all tumors with locoregional spread or distant metastases (FIGO stage II, III, IV) [Level III, Grade A]. ${ }^{1,}$, 22, 23, 25

- In unresectable tumors, up-front chemotherapy may be considered followed by delayed tumor resection [Level IV, Grade C].

- All other histologic subtypes of SCSTs (different from juvenile GrCTs and SLCTs) rarely present beyond stage IA and rarely require adjuvant chemotherapy [Level IV, Grade D] ${ }^{21}$ 
- Chemotherapy is chosen in analogy to GCT protocols and commonly includes cisplatin-based regimen (e.g. bleomycin-etoposide-cisplatin or etoposide-ifosfamide-cisplatin) [Level III, Grade A] (Table $\mathrm{V}) .1,25$

- In stage IC tumors, (three to) four cycles of chemotherapy and in stage II, III, IV tumors four cycles of chemotherapy are recommended, with second look surgery in case of initial macroscopic incomplete resection or residual disease [Level IV, Grade B]. Some study groups recommend a minimum of four cycles of chemotherapy, with escalation to up to six cycles in metastatic tumors [Level IV, Grade C].

- Radiotherapy is not routinely recommended [Level IV, Grade E]

- In case of insufficient response or tumor progression, therapy intensification can be considered on an individual basis, after discussion with national and international experts. Prognosis of these patients is poor. Therapeutic options include addition of bevacizumab, HIPEC (hyperthermic intraperitoneal chemotherapy with cytoreductive surgery), regional deep hyperthermia in combination with platinbased chemotherapy, high dose chemotherapy with autologous hematopoietic stem cell transplantation, and radiotherapy [Level V, Grade C]. ${ }^{27,} 28$

\section{Follow-up}

- Regular follow-up is recommended, at least for the first five to ten years [Level IV, Grade B].

- As up to $10 \%$ of patients may develop metachronous contralateral tumors, long-term follow-up may be offered [Level IV, Grade B]. ${ }^{16,18}$

- In adult $\mathrm{GrCTs}$, longer follow-up is recommended, because these tumors may recur after more than ten years [Level IV, Grade B]. ${ }^{12}$

- In DICER 1 positive tumors, life long surveillance is recommended, because DICER1 associated tumors may develop even at older age [Level IV, Grade A]. ${ }^{16}$

- Follow-up investigations include anamnesis, physical examination, and measurement of serum tumor markers only if these have been elevated perioperatively [Level IV, Grade A].

- In SLCTs with DICER1 pathogenic variant, thyroid function and structure should be monitored with ultrasound and laboratory investigations (association with multinodular goitre) at diagnosis and then at least every two years [Level IV, Grade B]..$^{3,16}$

- Radiographic follow-up includes pelvic and abdominal ultrasound, in three-monthly intervals during the first three years after diagnosis and in increasing intervals thereafter [Level IV, Grade B].

- Abdominal MRI is recommended in case of equivocal findings and in (adolescent) patients with poor visibility on ultrasound [Level IV, Grade B].

- Routine chest X-ray is not recommended for follow-up [Level IV, Grade E].

\section{Open questions to be addressed in the future}

The standardization of diagnostic assessment, risk stratification and therapy as well as participation in international registries will advance the knowledge of the biology and the clinical behaviour of SCSTs. However, due to rarity and heterogeneity of these tumors, randomized therapeutic studies will be impossible, even at the international level. Thus, research will have to focus on biological studies that may reveal the genetic basis of tumor development and risk constellations within tumor predisposition syndromes. Moreover, for testicular SCSTs, the evaluation of surgical data may address whether testis sparing may be feasible and safe. In contrast, the focus in OSCSTs will remain in the optimal risk stratification in tumors with highrisk histology and stage IC tumors. Last, effective salvage strategies must be developed in the context of the growing genetic and biological data on the rare cases of recurrent ovarian SCSTs, which have a very unfavourable prognosis. 


\section{Legends:}

Table 1:Histologic differentiation of testicular and ovarian sex cord stromal tumors in children and adolescents, their relative frequencies, characteristic age at presentation and associated genetic aberrations ${ }^{1,7,21,23}$

Table 2: Staging according to the revised International Federation of Gynecologic Oncology (FIGO)/WHO staging system ${ }^{29-31}$

Table 3: Specific diagnostic strategy in testicular or ovarian sex cord stromal tumors (from Schneider et al, $\left.2012^{1}\right)$

Table 4: Proposed therapeutic algorithm in testicular and ovarian sex cord stromal tumors (from Schneider et al, 2012 $2^{1}$ )

Table 5: Cisplatin-based chemotherapy regimen currently in use for the treatment of malignant germ cell tumors and sex cord stromal tumors (from Schneider et al, 2012 ${ }^{1}$ )

\section{References:}

1. Schneider DT, Terenziani M, Cecchetto G, Olson TA. Gonadal and Extragonadal Germ Cell Tumors, Sex Cord Stromal Tumors and Rare Gonadal Tumors. In: Schneider DT, Brecht IB, Oslon TA, Ferrari A, eds. Rare tumors in children and adolescents. Heidelberg: Springer, 2012: 327-402.

2. Bauer AJ, Stewart DR, Kamihara J, Harris AK, Turner J, Shah R, Schneider KW, Schneider K, Carr AG, Harney LA, Frazier AL, Orbach D, Schneider DT, Malkin D, Dehner LP, Messinger YH, Hill DA, Schultz KAP. DICER1 and Associated Conditions: Identification of At-risk Individuals and Recommended Surveillance Strategies-Response. Clin Cancer Res .2019;25:1689-1690.

3. Rio Frio T, Bahubeshi A, Kanellopoulou C, Hamel N, Niedziela M, Sabbaghian N, Pouchet C, Gilbert L, O'Brien PK, Serfas K, Broderick P, Houlston RS, Lesueur F, Bonora E, Muljo S, Schimke RN, BouronDal Soglio D, Arseneau J, Schultz KA, Priest JR, Nguyen VH, Harach HR, Livingston DM, Foulkes WD, Tischkowitz M. DICER1 mutations in familial multinodular goiter with and without ovarian Sertoli-Leydig cell tumors.JAMA .2011;305:68-77.

4. Schultz KAP, Harris AK, Finch M, Dehner LP, Brown JB, Gershenson DM, Young RH, Field A, Yu W, Turner J, Cost NG, Schneider DT, Stewart DR, Frazier AL, Messinger Y, Hill DA. DICER1-related SertoliLeydig cell tumor and gynandroblastoma: Clinical and genetic findings from the International Ovarian and Testicular Stromal Tumor Registry. Gynecol Oncol .2017;147:521-527.

5. Luckie TM, Danzig M, Zhou S, Wu H, Cost NG, Karaviti L, Venkatramani R. A Multicenter Retrospective Review of Pediatric Leydig Cell Tumor of the Testis. J Pediatr Hematol Oncol .2019;41:74-76.

6. Cecchetto G, Alaggio R, Bisogno G, Virgone C, Dall'Igna P, Terenziani M, Boldrini R, D'Onofrio V, Ferrari A, Bernini G. Sex cord-stromal tumors of the testis in children. A clinicopathologic report from the Italian TREP project. J Pediatr Surg .2010;45:1868-1873.

7. Hofmann M, Schlegel PG, Hippert F, Schmidt P, von-Schweinitz D, Leuschner I, Göbel U, Calaminus G, Schneider DT, MAKEI SG. Testicular sex cord stromal tumors: analysis of patients from the MAKEI study.Pediatr Blood Cancer .2013;60:1651-1655.

8. Fresneau B, Orbach D, Faure-Conter C, Verité C, Castex MP, Kalfa N, Martelli H, Patte C. Sex-cord stromal tumors in children and teenagers: Results of the TGM-95 study. Pediatr Blood Cancer .2015

9. Tröbs RB, Krauss M, Geyer C, Tannapfel A, Körholz D, Hirsch W. Surgery in infants and children with testicular and paratesticular tumours: a single centre experience over a 25-year-period. Klin Padiatr .2007;219:146-151. 
10. Schultz KA, Harris A, Messinger Y, Sencer S, Baldinger S, Dehner LP, Hill DA. Ovarian tumors related to intronic mutations in DICER1: a report from the international ovarian and testicular stromal tumor registry. Fam Cancer .2016;15:105-110.

11. Clement PB, Young RH, Scully RE. Clinical syndromes associated with tumors of the female genital tract.SeminDiagnPathol .1991;8:204-233.

12. Young RH. Sex cord-stromal tumors of the ovary and testis: their similarities and differences with consideration of selected problems. ModPathol .2005;18 Suppl 2:S81-S98.

13. Kalfa N, Ecochard A, Patte C, Duvillard P, Audran F, Pienkowski C, Thibaud E, Brauner R, Lecointre C, Plantaz D, Guedj AM, Paris F, Baldet P, Lumbroso S, Sultan C. Activating mutations of the stimulatory g protein in juvenile ovarian granulosa cell tumors: a new prognostic factor. J Clin Endocrinol Metab .2006;91:1842-1847.

14. Slade I, Bacchelli C, Davies H, Murray A, Abbaszadeh F, Hanks S, Barfoot R, Burke A, Chisholm J, Hewitt M, Jenkinson H, King D, Morland B, Pizer B, Prescott K, Saggar A, Side L, Traunecker H, Vaidya S, Ward P, Futreal PA, Vujanic G, Nicholson AG, Sebire N, Turnbull C, Priest JR, Pritchard-Jones K, Houlston R, Stiller C, Stratton MR, Douglas J, Rahman N. DICER1 syndrome: clarifying the diagnosis, clinical features and management implications of a pleiotropic tumour predisposition syndrome.J Med Genet .2011;48:273-278.

15. Whitcomb RW, Calkins JW, Lukert BP, Kyner JL, Schimke RN. Androblastomas and thyroid disease in postmenopausal sisters. Obstet Gynecol .1986;67:89S-91S.

16. Schultz KAP, Williams GM, Kamihara J, Stewart DR, Harris AK, Bauer AJ, Turner J, Shah R, Schneider K, Schneider KW, Carr AG, Harney LA, Baldinger S, Frazier AL, Orbach D, Schneider DT, Malkin D, Dehner LP, Messinger YH, Hill DA. DICER1 and Associated Conditions: Identification of At-risk Individuals and Recommended Surveillance Strategies .Clin Cancer Res .2018;24:2251-2261.

17. Young RH, Welch WR, Dickersin GR, Scully RE. Ovarian sex cord tumor with annular tubules: review of 74 cases including 27 with Peutz-Jeghers syndrome and four with adenoma malignum of the cervix. Cancer $.1982 ; 50: 1384-1402$.

18. Schneider DT, Orbach D, Cecchetto G, Stachowicz-Stencel T, Brummel B, Brecht IB, Bisogno G, Ferrari A, Reguerre Y, Godzinski J, Bien E, Calaminus G, Göbel U, Patte C. Ovarian Sertoli Leydig cell tumours in children and adolescents: an analysis of the European Cooperative Study Group on Pediatric Rare Tumors (EXPeRT). Eur J Cancer .2015;51:543-550.

19. Schneider DT, Calaminus G, Göbel U. Diagnostic value of alpha 1-fetoprotein and beta-human chorionic gonadotropin in infancy and childhood. Pediatr Hematol Oncol .2001;18:11-26.

20. Schultz KA, Harris A, Williams GM, Baldinger S, Doros L, Valusek P, Frazier AL, Dehner LP, Messinger Y, Hill DA. Judicious DICER1 testing and surveillance imaging facilitates early diagnosis and cure of pleuropulmonary blastoma. Pediatr Blood Cancer .2014;61:1695-1697.

21. Schneider DT, Jänig U, Calaminus G, Göbel U, Harms D. Ovarian sex cord-stromal tumors-a clinicopathological study of 72 cases from the Kiel Pediatric Tumor Registry. Virchows Arch .2003;443:549-560.

22. Cecchetto G, Ferrari A, Bernini G, Alaggio R, Collini P, Virgone C, Terenziani M, Dall'igna P, Cozza R, Conte M, Bisogno G. Sex cord stromal tumors of the ovary in children: a clinicopathological report from the Italian TREP project. Pediatr Blood Cancer .2011;56:1062-1067.

23. Schultz KA, Schneider DT, Pashankar F, Ross J, Frazier L. Management of ovarian and testicular sex cord-stromal tumors in children and adolescents. J Pediatr Hematol Oncol .2012;34 Suppl 2:S55-63.

24. Schultz KA, Harris AK, Schneider DT, Young RH, Brown J, Gershenson DM, Dehner LP, Hill DA, Messinger YH, Frazier AL. Ovarian Sex Cord-Stromal Tumors. J Oncol Pract .2016;12:940-946. 
25. Sessa C, Schneider DT, Planchamp F, Baust K, Braicu EI, Concin N, Godzinski J, McCluggage WG, Orbach D, Pautier P, Peccatori FA, Morice P, Calaminus G. ESGO-SIOPE guidelines for the management of adolescents and young adults with non-epithelial ovarian cancers. Lancet Oncol .2020;21:e360-e368.

26. Schneider DT, Calaminus G, Wessalowski R, Pathmanathan R, Selle B, Sternschulte W, Harms D, Göbel U, Wessalowksi R. Ovarian sex cord-stromal tumors in children and adolescents. J Clin Oncol .2003;21:23572363 .

27. Lashkari HP, Nash R, Albanese A, Okoye B, Millar R, Pritchard-Jones K. Treatment of high risk SertoliLeydig cell tumors of the ovary using a gonadotropin releasing hormone $(\mathrm{GnRH})$ analog. Pediatr Blood Cancer .2013;60:E16-8.

28. Benesch M, Lackner H, Pilhatsch A, Gürtl-Lackner B, Schwinger W, Urban C. Long-term Remission in a Female With Multiple Relapsed Juvenile Granulosa Cell Tumor. J Pediatr Hematol Oncol .2015;37:e486-9.

29. Benedet JL, Bender H, Jones H,III, Ngan HY, Pecorelli S. FIGO staging classifications and clinical practice guidelines in the management of gynecologic cancers. FIGO Committee on Gynecologic Oncology. IntJGynaecolObstet .2000;70:209-262.

30. Meinhold-Heerlein I, Fotopoulou C, Harter P, Kurzeder C, Mustea A, Wimberger P, Hauptmann S, Sehouli J. The new WHO classification of ovarian, fallopian tube, and primary peritoneal cancer and its clinical implications. Arch Gynecol Obstet .2016

31. Rosendahl M, Høgdall CK, Mosgaard BJ. Restaging and Survival Analysis of 4036 Ovarian Cancer Patients According to the 2013 FIGO Classification for Ovarian, Fallopian Tube, and Primary Peritoneal Cancer. Int J Gynecol Cancer .2016

\section{Hosted file}

Table 1.pdf available at https://authorea.com/users/395977/articles/509102-consensusrecommendations-from-expert-partn-er-groups-for-the-diagnosis-and-therapy-of-sex-cordstromal-tumors-in-children-and-adolescents

\section{Hosted file}

Table 2.pdf available at https://authorea.com/users/395977/articles/509102-consensusrecommendations-from-expert-partn-er-groups-for-the-diagnosis-and-therapy-of-sex-cordstromal-tumors-in-children-and-adolescents

\section{Hosted file}

Table 3.pdf available at https://authorea.com/users/395977/articles/509102-consensusrecommendations-from-expert-partn-er-groups-for-the-diagnosis-and-therapy-of-sex-cordstromal-tumors-in-children-and-adolescents

\section{Hosted file}

Table 4.pdf available at https://authorea.com/users/395977/articles/509102-consensusrecommendations-from-expert-partn-er-groups-for-the-diagnosis-and-therapy-of-sex-cordstromal-tumors-in-children-and-adolescents

\section{Hosted file}

Table 5.pdf available at https://authorea.com/users/395977/articles/509102-consensusrecommendations-from-expert-partn-er-groups-for-the-diagnosis-and-therapy-of-sex-cordstromal-tumors-in-children-and-adolescents 